\title{
Crescimento de juvenis de jundiá (Rhamdia quelen) com diferentes proporções de amilose:amilopectina na dieta
}

\author{
[Growth of jundiá juveniles (Rhamdia quelen) with different proportions of \\ amylose:amylopectin in diet] \\ F.A. Pedron, J. Radünz Neto, L.P. Silva, G.T. Bergamin, D. Maschio, S.G. Martinelli, \\ M.A. DellaFlora, V. Corrêia \\ Laboratório de Piscicultura - Departamento de Zootecnia \\ Universidade Federal de Santa Maria \\ Av. Roraima, n. 1000 - Cidade Universitária \\ 97105-900 - Santa Maria, RS \\ RESUMO
}

\begin{abstract}
Crescimento e características de carcaça do jundiá (Rhamdia quelen) foram avaliados após 60 dias de alimentação com diferentes proporções de amilose:amilopectina na dieta. Foram criados 240 peixes (peso inicial de $34,3 \pm 4,3 \mathrm{~g}$ ) em sistema de recirculação de água constituído de 12 unidades experimentais de 280L. Foram testadas três dietas com as proporções amilose:amilopectina de: T417 = com $26 \%$ de amilose, $\mathrm{T} 416=\mathrm{com} 16 \%$ de amilose e TMOCHI $=$ com $0 \%$ de amilose. Os peixes foram alimentados duas vezes por dia, às $8 \mathrm{~h}$ e $30 \mathrm{~min}$ e às 16 horas. A cada 15 dias, foram feitas biometrias para ajuste da quantidade de alimento ofertado. A proporção amilose:amilopectina no amido das dietas não influenciou o crescimento, os rendimentos de carcaça e a composição corporal dos peixes. Conclui-se que o jundiá tem potencial para utilizar fontes de amido compostas por até $26 \%$ de amilose sem alterar a digestibilidade dos nutrientes e a deposição de gordura.
\end{abstract}

Palavras-chave: jundiá, carboidrato, amido, digestibilidade, glicose

\begin{abstract}
The growth and carcass traits of jundiá (Rhamdia quelen) after 60 days being fed with different amylose:amylopectin ratio in diet were evaluated. Two hundred and forty fish (initial weight of $34.3 \pm 4.3 \mathrm{~g}$ ) were raised in water re-use system with 12 units of $280 \mathrm{~L}$. Three diets were tested with amylose: amylopectin ratios: $T 417=26 \%$ amylose, $T 416=16 \%$ amylose and TMOCHI $=0 \%$ amylose . The fish were fed twice a day at 8:30 and 16:00h. Every 15 days the amount of food offered was ajusted. The amylose:amylopectin ratio in the starch of the diet did not affect growth, carcass and body composition of fish. This demonstrates that the jundiá has the potential to use starchy sources consisting of up to $26 \%$ amylose without altering the digestibility of nutrients and fat deposition.
\end{abstract}

Keywords: jundiá, carbohydrate, starch, digestibility, glucose

\section{INTRODUÇÃO}

Com intuito de melhorar a utilização dos alimentos pelos peixes, têm-se avaliado alimentos de diferentes forma, composição e processamento, para maximizar o crescimento e reduzir a eliminação de resíduos, principalmente os nitrogenados. A utilização equilibrada de proteína e energia da dieta permite um bom crescimento e reduz a eliminação de excrementos. Esse ponto é chamado de efeito poupador de proteína (Salhi et al., 2004).

Os carboidratos são fontes energéticas de baixo custo que podem ser utilizadas em dietas, no entanto sua eficiência no efeito poupador de

Recebido em 23 de julho de 2010

Aceito em 2 de agosto de 2011

E-mail:pedron.ufsm@gmail.com 
proteína nos peixes pode variar, influenciada por fatores como temperatura da água (Enes et al., 2008b), hábito alimentar (Shiau, 1997), espécie cultivada e tipo e quantidade de carboidrato (Hemre et al., 2002; Krogdahl et al., 2005).

O amido é um dos principais polissacarídeos digestíveis utilizados em dietas para peixes (Rawles e Lochmann, 2003). Vários trabalhos estudaram diferentes formas estruturais do amido, pela gelatinização ( $\mathrm{Fu}, 2005$; Young et al., 2006; Wu et al., 2007), pela fonte convencional (Hemre et al., 2002; Venou et al., 2003) e pelas fontes como mono e dissacarídeos (Hutchins et al., 1998), e demonstram que a composição amídica tem efeito no aproveitamento do alimento e no crescimento dos peixes.

As formas moleculares do amido apresentam-se sobre dois tipos de cadeia, a amilose - cadeia linear de glicoses unidas por ligações $\alpha 1-4$ - e a amilopectina - cadeia ramificada de glicoses unidas por ligações $\alpha$ 1-4 e $\alpha$ 1-6 (Chen et al., 2009). A organização da amilose e da amilopectina nos grânulos de amido ainda não está bem elucidada. A relação amilose:amilopectina parece estar relacionada com a digestibilidade do amido (Zhou e Kaplan, 1997; Svihus et al., 2005), pois dietas com carboidratos que são digeridos lentamente, em geral, resultam em glicemia mais estável e em melhor crescimento (Wilson, 1994).

O jundiá (Rhamdia quelen) é um peixe que tem hábito alimentar onívoro, consequentemente com características compatíveis para aproveitar o amido dos alimentos. O objetivo do trabalho foi avaliar crescimento, rendimentos e composição corporais dos jundiás alimentados durante 60 dias com diferentes proporções de amilose:amilopectina na dieta.

\section{MATERIAL E MÉTODOS}

O trabalho foi realizado entre os meses de fevereiro e maio de 2008, com duração de 60 dias, e a coleta de fezes para predição da digestibilidade aparente foi realizada ao final do experimento. Foram utilizados 240 peixes de ambos os sexos, com peso médio inicial de $34,3 \pm 4,3 \mathrm{~g}$ da espécie Rhamdia quelen, distribuídos em 12 unidades experimentais com 20 peixes em cada. Os animais passaram por período de adaptação nas unidades experimentais 15 dias antes do início do experimento. $\mathrm{Na}$ criação dos peixes, foi utilizado circuito de recirculação de água com 18 unidades experimentais (280L) e filtragem biológica. Cada unidade tinha entrada e saída de água individual, além de oxigenadores auxiliares.

Para a coleta de fezes, foram acoplados ao circuito de recirculação seis tanques em forma cônica, com capacidade de 200L cada, com entrada e saída de água independentes, todos contendo um registro e um reservatório para sedimentação de fezes em sua extremidade inferior (adaptado de Guelph).

Para o monitoramento da qualidade da água, foram realizadas semanalmente análises dos seguintes parâmetros: $\mathrm{pH}$, alcalinidade total, amônia total, nitrito. Somente temperatura e oxigênio dissolvido foram diários. A leitura do $\mathrm{pH}$ foi feita com pHmetro digital. Os valores de oxigênio foram coletados com oxímetro digital (modelo 550A-YSI-Yellowsprings-EUA). Os parâmetros de qualidade de água do sistema de criação foram: temperatura $\left(22,64 \pm 2,35^{\circ} \mathrm{C}\right)$, amônia total $(0,08 \pm 0,06 \mathrm{ppm}), \quad$ nitrito $(0,01 \pm 0,01 \mathrm{ppm}), \quad$ alcalinidade $\quad(26,27 \pm 5,79 \mathrm{mg}$ $\left.\mathrm{CaCO}_{3} / \mathrm{L}\right), \mathrm{pH}(6,8 \pm 0,5)$ e oxigênio dissolvido $(7,26 \pm 0,66 \mathrm{ppm})$. Esses valores estão dentro da faixa considerada adequada para a criação da espécie (Gomes et al., 2000). Para a realização das análises, a água foi coletada na entrada do primeiro filtro biológico.

Foram testadas diferentes proporções amilose: amilopectina do amido. Para isso, utilizaram-se três variedades de arroz, produzidas pelo Instituto Rio-Grandense do Arroz: Mochi, IRGA 416 e IRGA 417, com 0\%, $16 \%$ e $26 \%$ de amilose, respectivamente (Tab. 1). A composição em aminoácidos das dietas foi ajustada às exigências do jundiá, conforme Meyer e Fracalossi (2005). Para a confecção das dietas, os ingredientes foram pesados e misturados, umedecidos e peletizados em moedor de carne, e elas foram levadas à estufa por $24 \mathrm{~h}\left(50^{\circ} \mathrm{C}\right)$. Após a secagem, as rações foram quebradas para a obtenção de grânulos com aproximadamente $5 \mathrm{~mm}$ de diâmetro. Nas dietas utilizadas para digestibilidade, foi adicionado $0,1 \%$ de marcador inerte $\left(\mathrm{Cr}_{2} \mathrm{O}_{3}\right)$ para determinação da digestibilidade das dietas por meio de cálculo. $\mathrm{O}$ marcador foi incorporado primeiramente aos 
ingredientes de pequeno volume, vitaminas, minerais e ao cloreto de sódio, e após, aos demais ingredientes.

$\mathrm{O}$ alimento foi fornecido duas vezes ao dia, às $8 \mathrm{~h}$ e $30 \mathrm{~min}$ e às $16 \mathrm{~h}$. A quantidade ofertada foi de $4 \%$ da biomassa/dia até os 45 dias e, após, foram ofertados 3\%/dia. Para manter a qualidade da água, foram realizadas sifonagens dos resíduos das caixas uma hora após a alimentação. Com a finalidade de ajustar a quantidade de ração ofertada, foram realizadas biometrias a cada 15 dias de experimento.
Para as coletas, foi utilizado sistema "Guelph" adaptado. Dos 12 tanques que formavam o circuito, seis tanques foram manejados por dia com a transferência dos animais para os tanques de coleta. Os animais que não foram para os tanques de coleta foram alimentados normalmente. Os peixes foram transferidos pela manhã, às oito horas, e retirados ao final da tarde, às $18 \mathrm{~h}$, e os intervalos de coletas foram de duas horas. $\mathrm{O}$ material coletado centrifugado $-\mathrm{e}$ dele retirado o excesso de água - foi seco em estufa a $50^{\circ} \mathrm{C}$.

Tabela 1. Composição das dietas experimentais expressa em porcentagem, segundo os tratamentos para o jundiá (Rhamdia quelen)

\begin{tabular}{|c|c|c|c|}
\hline Ingrediente & TMOCHI & T416 & T417 \\
\hline Farinha de carne suína & 25 & 25 & 25 \\
\hline Farelo de soja & 40 & 40 & 40 \\
\hline Arroz (0\% amilose) & 30 & - & - \\
\hline Arroz (16\% amilose) & - & 30 & - \\
\hline Arroz (26\% amilose) & - & - & 30 \\
\hline Óleo de soja & 2 & 2 & 2 \\
\hline Lisina & 0,05 & 0,05 & 0,05 \\
\hline Metionina & 0,17 & 0,17 & 0,17 \\
\hline Cloreto de sódio & 1 & 1 & 1 \\
\hline Vitaminas e minerais $^{1}$ & 1,99 & 1,99 & 1,99 \\
\hline Antioxidante $^{2}$ & 0,01 & 0,01 & 0,01 \\
\hline \multicolumn{4}{|l|}{ Composição analisada $^{3}$} \\
\hline Umidade & 12,13 & 13,52 & 12,32 \\
\hline Lipídios & 8,11 & 7,68 & 7,80 \\
\hline Cinzas & 8,44 & 9,26 & 9,08 \\
\hline Proteína bruta & 31,29 & 32,53 & 32,04 \\
\hline Amido disponível & 30,36 & 32,48 & 30,93 \\
\hline Energia digestível $(\mathrm{kcal} / \mathrm{kg})^{5}$ & 3278,9 & 3278,9 & 3278,9 \\
\hline Lisina $^{4}$ & 1,87 & 1,87 & 1,87 \\
\hline Metionina $^{4}$ & 0,68 & 0,68 & 0,68 \\
\hline Metionina + Cistina $^{4}$ & 0,94 & 0,94 & 0,94 \\
\hline Treonina $^{4}$ & 1,18 & 1,18 & 1,18 \\
\hline Triptofano 4 & 0,28 & 0,28 & 0,28 \\
\hline Valina $^{4}$ & 1,64 & 1,64 & 1,64 \\
\hline Isoleucina $^{4}$ & 1,19 & 1,19 & 1,19 \\
\hline Leucina $^{4}$ & 2,23 & 2,23 & 2,23 \\
\hline Fenilalanina $^{4}$ & 1,36 & 1,36 & 1,36 \\
\hline Histidina $^{4}$ & 0,76 & 0,76 & 0,76 \\
\hline Arginina $^{4}$ & 2,48 & 2,48 & 2,48 \\
\hline \multicolumn{4}{|c|}{ 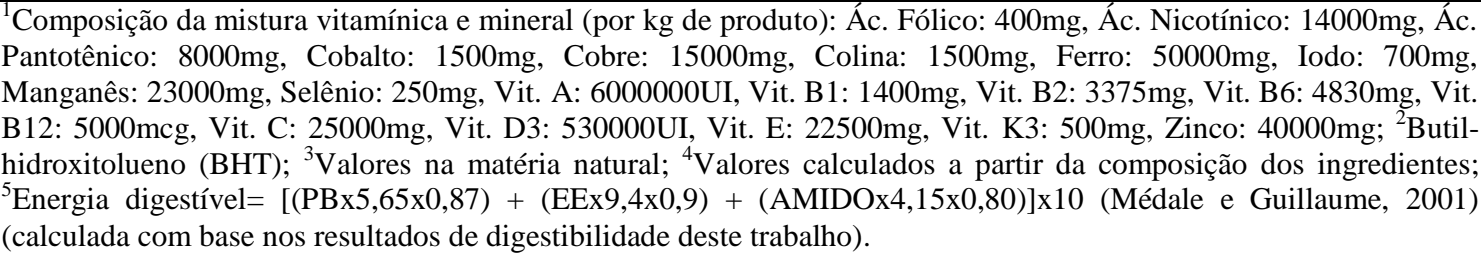 } \\
\hline
\end{tabular}


Após passarem por jejum de 24 horas, os peixes foram pesados individualmente para obtenção dos dados de crescimento: peso do peixe inteiro $(\mathrm{g})$; ganho em peso $(\mathrm{g})$; fator de condição $-\mathrm{FC}=$ $($ pesox 100$) /\left(\right.$ comprimento total $\left.^{3}\right) \quad-;$ taxa de crescimento específico $(\%$ por dia $)-\mathrm{TCE}=[(\ln$ $\mathrm{PF}$ - $\ln \mathrm{PI}) / \mathrm{d}]^{*} 100 \quad-$; taxa de eficiência proteica - ganho em peso/proteína consumida -; consumo alimentar diário e conversão alimentar aparente.

Para os dados de rendimentos, no início do experimento foram separados 10 peixes para obtenção dos dados iniciais. Na biometria de 60 dias, foram amostrados dois peixes por caixa, oito peixes por tratamento, para a coleta de amostras. Os peixes foram abatidos por hipotermia - imersão em água mais gelo 1:1 -, filetados e eviscerados, coletados e pesados os filés, fígado, trato gastrintestinal, gordura celomática. Com os dados, foram calculadas as seguintes variáveis: rendimento de carcaça; rendimento de filé (sem pele); índice hepatossomático; índice digestivossomático; índice de gordura celomática; coeficiente de retenção proteica $(\%)-\mathrm{CRP}=100 *[(\mathrm{Pf} * \mathrm{PBCf})$ - $(\mathrm{Pi} * \mathrm{PBCi})] / \mathrm{ACt}^{*} \mathrm{PBc}-$, em que: $\mathrm{Pf}=$ peso final; $\mathrm{Pi}=$ peso inicial; $\mathrm{PBCf}=$ proteína bruta na carcaça final; $\mathrm{PBCi}=$ proteína bruta na carcaça inicial; $\mathrm{ACt}=$ alimento consumido total; $\mathrm{PBc}=$ PB da dieta em \%.

Para a composição centesimal dos peixes, foram utilizados dois peixes por unidade experimental. Os valores de proteína bruta foram determinados pelo método de Kjeldahl com fator de 6,25. A matéria mineral e a umidade foram determinadas conforme metodologias da AOAC (Official..., 1995), e a fração lipídica pelo método de Bligh e Dyer (1959).

Para as dietas e para as fezes, foram realizadas análises da composição química. A proteína bruta foi determinada pelo método de Kjeldahl com fator de 6,25. A matéria seca e o amido foram determinados por metodologias da AOAC (Official..., 1995). A concentração do $\mathrm{Cr}_{2} \mathrm{O}_{3}$ nas fezes e na dieta foi determinada por espectrofotometria (Bremer Neto et al., 2003). Para o cálculo do coeficiente de digestibilidade, usou-se a fórmula: $\mathrm{CDa}=100-\left[100\left(\% \mathrm{Cr}_{2} \mathrm{O}_{3} \mathrm{~d}\right.\right.$ / $\left.\left.\% \mathrm{Cr}_{2} \mathrm{O}_{3} \mathrm{f}\right) \times(\% \mathrm{Nf} / \% \mathrm{Nd})\right]$, em que: $\mathrm{CDa}=$ coeficiente de digestibilidade aparente; $\mathrm{Cr}_{2} \mathrm{O}_{3} \mathrm{~d}=$ óxido de cromo na dieta; $\mathrm{Cr}_{2} \mathrm{O}_{3} \mathrm{f}=$ óxido de cromo nas fezes; $\mathrm{Nd}=$ nutriente na dieta; $\mathrm{Nf}=$ nutriente nas fezes.

O delineamento experimental foi inteiramente ao acaso, com três tratamentos e quatro repetições. Os dados apresentando distribuição normal foram realizados análises de variância. As variáveis foram comparadas pelo teste de Duncan $(\mathrm{P}<0,05)$. Para as análises, foi utilizado o programa estatístico SAS (Statistical..., 2001).

\section{RESULTADOS}

Não houve diferença significativa entre os tratamentos testados para os resultados de crescimento (Tab. 2). No entanto, os valores de ganho de peso e taxa de crescimento específico demonstram que os peixes tiveram bom crescimento. O consumo alimentar diário (\%) foi estimado abaixo do ofertado aos peixes, proporcionando, dessa forma, maior conversão alimentar aparente. Ainda, essas últimas variáveis apresentaram correlação negativa com coeficiente de retenção proteica $(-0,71)$ e com taxa de eficiência proteica $(-0,76)$. Isso indica que o aumento do consumo de alimento resulta em tendência em diminuir o aproveitamento proteico, dentro das condições experimentais.

Os rendimentos de carcaça e filé não foram influenciados pela proporção amilose:amilopectina no amido da dieta. Da mesma forma, os índices hepatossomático e digestivossomático não diferiram entre os tratamentos, no entanto apresentaram alta correlação $(0,73)$ caracterizada pelo maior peso do fígado em razão do aumento do comprimento do trato digestivo. $O$ índice de gordura celomática não foi influenciado pela proporção amilose:amilopectina (Tab. 3).

Os valores de composição corporal dos peixes, como umidade, cinzas, lipídios e proteína bruta não diferiram entre tratamentos (Tab. 4), demonstrando que a proporção amilose:amilopectina não afeta de forma significativa a composição do corpo do peixe. Isto é reforçado pelos resultados da gordura total depositada e da proteína total depositada. Apenas a amostra inicial da proteína bruta difere da amostra ao final do experimento. 
Tabela 2. Características de crescimento de jundiás alimentados com diferentes proporções de amilose:amilopectina

\begin{tabular}{lcccc} 
& TMOCHI & T416 & T417 & DPR \\
\hline PF & 82,5 & 84,9 & 84,9 & 7,7 \\
GP & 48,0 & 50,4 & 50,2 & 7,7 \\
TCE & 1,44 & 1,50 & 1,49 & 0,15 \\
FC & 0,97 & 1,00 & 0,98 & 0,07 \\
CAA & 2,05 & 1,98 & 1,95 & 0,22 \\
CAD & 2,76 & 2,75 & 2,73 & 0,05 \\
TEP & 1,46 & 1,49 & 1,52 & 0,15 \\
\hline
\end{tabular}

$\mathrm{PF}=$ peso final; $\mathrm{GP}=$ ganho de peso; $\mathrm{TCE}=$ taxa de crescimento específico; $\mathrm{FC}=$ fator de condição; CAA $=$ conversão alimentar aparente; $\mathrm{CAD}=$ consumo de alimento diário $(\% \mathrm{PV})$; TEP $=$ taxa de eficiência proteica; TMOCHI $=0 \%$ amilose; $\mathrm{T} 416=16 \%$ de amilose; $\mathrm{T} 417=26 \%$ de amilose; $\mathrm{DPR}=$ desvio-padrão residual.

Não houve diferença significativa entre os tratamentos pelo teste Duncan $(P>0,05)$.

Tabela 3. Rendimento e índice corporal de jundiás alimentados com diferentes proporções de amilose:amilopectina

\begin{tabular}{lcccc}
\hline & TMOCHI & T416 & T417 & DPR \\
\hline RC (\%) & 87,0 & 85,3 & 86,6 & 1,16 \\
RF (\%) & 34,0 & 32,5 & 32,1 & 1,69 \\
IDS (\%) & 2,54 & 2,45 & 2,52 & 0,46 \\
IHS (\%) & 0,98 & 0,81 & 0,93 & 0,20 \\
IGC (\%) & 3,01 & 3,78 & 3,01 & 1,07 \\
CRP & 25,55 & 26,37 & 25,46 & 2,20 \\
\hline
\end{tabular}

$\mathrm{RC}=$ rendimento de carcaça; $\mathrm{RF}=$ rendimento de filé; IDS = índice digestivossomático; IHS = índice hepatossomático; IGC = índice de gordura celomática; $\mathrm{CRP}=$ coeficiente de retenção proteica; $\mathrm{TMOCHI}=0 \%$ amilose; T416=16\% de amilose; T417=26\% de amilose; DPR = desvio padrão residual.

Não houve diferença significativa entre os tratamentos pelo teste Duncan $(\mathrm{P}>0,05)$.

Tabela 4. Valores de composição corporal (\%) de jundiás alimentados com diferentes proporções de amilose:amilopectina na ração

\begin{tabular}{lccccc} 
& Inicial $^{1}$ & TMOCHI & T416 & T417 & DPR \\
\hline Umidade & 71,61 & 70,30 & 68,85 & 70,13 & 1,79 \\
Cinzas $^{2}$ & 3,16 & 2,93 & 3,03 & 3,00 & 0,22 \\
Proteína bruta $^{2}$ & 12,70 & 15,55 & 15,54 & 15,34 & 0,64 \\
Gordura & 11,41 & 12,86 & 13,36 & 13,73 & 1,78 \\
GTD & - & 6,67 & 7,43 & 7,74 & 1,51 \\
PTD & - & 8,47 & 8,67 & 8,84 & 0,54 \\
\hline
\end{tabular}

${ }^{1}$ Valores iniciais do experimento. ${ }^{2}$ Diferença significativa em relação à inicial pelo teste de Dunnet. GTD = gordura total depositada; $\mathrm{PTD}=$ proteína total depositada; $\mathrm{TMOCHI}=0 \%$ amilose; $\mathrm{T} 416=16 \%$ de amilose; $\mathrm{T} 417=26 \%$ de amilose; DPR = desvio-padrão residual.

Não houve diferença significativa entre os tratamentos pelo teste Duncan $(\mathrm{P}>0,05)$.

Tabela 5. Digestibilidade dos nutrientes de jundiás alimentados com diferentes proporções de amilose:amilopectina

\begin{tabular}{lcccc}
\hline & TMOCHI & T416 & T417 & dpr \\
\hline DMS & 68,43 & 70,76 & 71,86 & 3,34 \\
DPB & 87,18 & 86,18 & 89,11 & 4,21 \\
DAM & 82,14 & 78,78 & 82,11 & 2,23 \\
\hline
\end{tabular}

DMS = digestibilidade da matéria seca; DPB = digestibilidade da proteína bruta; DAM = digestibilidade do amido; TMOCHI $=0 \%$ amilose; T416 $=16 \%$ de amilose; T417 $=26 \%$ de amilose; DPR $=$ desvio-padrão residual.

Não houve diferença significativa entre os tratamentos pelo teste de Duncan $(\mathrm{P}>0,05)$. 
A digestibilidade da matéria seca, proteína bruta e amido não foi influenciada pela proporção amilose:amilopectina do alimento.

\section{DISCUSSÃO}

O tipo de cadeia e a complexidade do amido são fatores que atuam de forma significativa no aproveitamento energético dos alimentos, e, quando metabolizados eficientemente, os carboidratos (amido) proporcionam rápido crescimento, melhor utilização proteica e animal saudável (Lin et al., 1997; Hemre et al., 2002; Peres e Oliva-Teles, 2002; Enes et al., 2006; Wu et al., 2007).

Os resultados de crescimento aos 60 dias experimentais demonstraram que a relação amilose:amilopectina do amido da dieta não alterou o crescimento dos peixes, semelhante a outros trabalhos em que a composição estrutural do amido (amilose:amilopectina) não influenciou de forma expressiva o crescimento de duas espécies, Dicentrarchus labrax (Enes et al., 2006) e Sparus aurata (Enes et al., 2008a). No entanto, para o "sunshine bass" (Morone chrysops $\bigcirc$ x $M$. saxatilis $\widehat{O})$, a proporção de $70 \%$ de amilose e $30 \%$ amilopectina apresentou melhor crescimento dos peixes quando comparada com menores porcentagens de amilose - 30:70 e 0:100 de amilose:amilopectina (Rawles e Lochmann, 2003). Isto sugere que a proporção entre essas formas moleculares do amido pode apresentar resultados diferenciados conforme a espécie, o hábito alimentar e a quantidade de amido incluído na dieta (Gaylord et al., 2009).

A proporção de amilose:amilopectina na dieta pode influenciar o rendimento de cortes e os índices corporais dos peixes (Enes et al., 2006), pois a utilização energética é diferenciada conforme essa relação (Svihus et al., 2005). O uso de carboidratos de maior digestibilidade em dietas pode resultar em acúmulo de gordura na cavidade celomática dos animais (Hemre et al., 2002). Segundo essa afirmação, Rawles e Lochmann (2003) demonstraram que, com maiores proporções de amilose, 30 a $70 \%$, podem-se obter peixes com menor teor de gordura celomática. Esse aspecto não foi observado no presente trabalho, pois não foi verificada diferença no acúmulo de gordura celomática entre os tratamentos. O mesmo fato ocorreu para o rendimento de carcaça e de filé, e índices hepatossomático e digestivossomático (Tab. 3). Resultados encontrados por Enes et al. (2008a) também mostraram índice hepatossomático igual para dietas com variadas proporções de amilose:amilopectina, independentemente da porcentagem de inclusão de amido. No entanto, com porcentagens de $10 \mathrm{e}$ $20 \%$ de amido na dieta, a maior porcentagem de amido "ceroso", $1 \%$ de amilose, resultou no menor tamanho do fígado em relação ao amido "nativo", 30\% de amilose (Enes et al., 2006). Diferentemente dessa afirmação, maiores quantidades de amilose na dieta do "sunshine bass" resultaram em menor índice hepatossomático (Rawles e Lochmann, 2003). Contudo, a alteração no volume hepático pode ser causada pela forma como o organismo do peixe metaboliza a fonte energética em conjunto com os outros nutrientes, como também pelo manejo adotado e pela temperatura da água.

A utilização da glicose como fonte energética diminui a oxidação lipídica e estimula a biossíntese de gordura (Hemre et al., 2002). Considerando isso, a composição química corporal dos peixes torna-se uma informação importante quanto ao aspecto nutricional, porém também pode promover maior deposição proteica por efeito poupador de proteína (Lin et al., 1997; Shiau, 1997; Singh et al., 2006).

O efeito da proporção amilose:amilopectina não causou alteração na composição corporal dos peixes (Tab. 4), semelhante aos resultados de Enes et al. (2006) e Enes et al. (2008a), que não observaram influência da quantidade de amilose na composição corporal dos peixes. Essa mesma observação foi feita para a composição do músculo do "sunshine bass" (Rawles e Lochmann, 2003). A composição química dos peixes parece não sofrer influência significativa da fonte de carboidrato da dieta (Hemre e Hansen, 1998; Young et al., 2006; Hemre et al., 2007; Wu et al., 2007).

Os resultados deste trabalho confirmam a dependência do crescimento na digestibilidade dos nutrientes. Como não ocorreu diferença na digestibilidade, possivelmente esse efeito foi refletido no desenvolvimento dos peixes. Segundo Enes et al. (2006) e Enes et al. (2008a), a proporção amilose:amilopectina não causa diferença na digestibilidade dos nutrientes. Os 
jundiás apresentaram bom crescimento e rendimento corporal quando comparados com os de outros trabalhos realizados com juvenis dessa espécie (Lazzari et al., 2008; Losekann et al., 2008; Pedron et al., 2008; Corrêia et al., 2009). Isto fortalece a característica de habito alimentar onívoro do jundiá, pois o bom desenvolvimento com grandes quantidades de amido (28\%) sugere que essa espécie é promissora em utilizar fontes energéticas vegetais.

\section{CONCLUSÕES}

O jundiá tem potencial para aproveitar fontes com diferentes proporções de amilose:amilopectina na dieta. Os rendimentos de carcaça e a composição corporal não são afetados pela composição amídica, principalmente em relação ao acúmulo de gordura.

\section{AGRADECIMENTOS}

Ao Instituto Rio Grandense do Arroz (IRGA), pela doação dos ingredientes; à CAPES, pela bolsa de doutorado de Fábio de Araújo Pedron; ao $\mathrm{CNPq}$, pela concessão de bolsa de produtividade em pesquisa de João Radünz Neto e Leila Picolli da Silva.

\section{REFERÊNCIAS BIBLIOGRÁFICAS}

BLIGH, E.G.; DYER, W.J. A rapid method of total lipid extraction and purification. Can. J. Biochem. Physiol., v.37, p.911-917, 1959.

BREMER NETO, H.; GRANER, C.A.F.; PEZZATO, L.E. et al. Diminuição do teor de óxido de crômio (III) usado como marcador externo. Rev. Bras. Zootec., v.32, p.249-255, 2003.

CHEN, P.; YU, L.; SIMON, G. et al. Morphologies and microstructures of cornstarches with different amylose-amylopectin ratios studied by confocal laser scanning microscope. J. Cereal Sci., v.50, p.241-247, 2009.

CORRÊIA, V.; RADÜNZ NETO, J.; LAZZARI, R. et al. Crescimento de jundiá e carpa húngara criados em sistema de recirculação de água. Cienc. Rural, v.39, p.1533-1539, 2009.

ENES, P.; PANSERAT, S.; KAUSHIK, S. et al. Effect of normal and waxy maize starch on growth, food utilization and hepatic glucose metabolism in European sea bass (Dicentrarchus labrax) juveniles. Comp. Biochem. Phisiol., Part A, v.143, p.89-96, 2006.
ENES, P.; PANSERAT, S.; KAUSHIK, S. et al. Growth performance and metabolic utilization of diets with native and waxy maize starch by gilthead sea bream (Sparus aurata) juveniles. Aquaculture, v.274, p.101-108, 2008a.

ENES, P.; PANSERAT, S.; KAUSHIK, S. et al. Hepatic glucokinase and glucose-6-phosphate responses to dietary glucose and starch in gilthead sea bream (Sparus aurata) juveniles reared at two temperatures. Comp. Biochem. Phisiol., Part A, v.149, p.80-86, 2008b.

FU, S.J. The growth performance of southern catfish fed diets with raw, precooked and glucose at two levels. Aquacult. Nutr., v.11, p.257-261, 2005.

GAYLORD, T.G.; BARROWS, F.T.; RAWLES, S.D. et al. Apparent digestibility of nutrients and energy in extruded diets from cultivars of barley and wheat selected for nutritional quality in rainbow trout Oncorhynchus mykiss. Aquacult. Nutr., v.15, p.306312, 2009 .

GOMES, L.C.; GOLOMBIESKI, J.I.; CHIPPARIGOMES, A.R. et al. Biologia do jundiá Rhamdia quelen (TELEOSTEI, PIMELODIDAE). Cienc. Rural, v.30, p.179-185, 2000.

HEMRE, G-I.; HANSEN, T. Utilization of different dietary starch sources and tolerance to glucose loading in Atlantic salmon (Salmo salar), during parr-smolt transformation. Aquaculture, v.161, p.145-157, 1998.

HEMRE, G-I.; MOMMSEN, T.P.; KROGDAHL, Á. Carbohydrates in fish nutrition: effects on growth, glucose metabolism and hepatic enzymes. Aquacult. Nutr., v.8, p.175-194, 2002.

HEMRE, G-I.; SAGSTAD, A.; BAKKEMCKELLEP, A.M. et al. Nutritional, physiological, and histological responses in Atlantic salmon, Salmo salar L. fed diets with genetically modified maize. Aquacult. Nutr., v.13, p.186-199, 2007.

HUTCHINS, C.G.; RAWLES, S.D.; GLATLIN III, D.M. Effects of dietary carbohydrate kind and level on growth, body composition and glycemic response of juvenile sunshine bass (Morone chrysops $\bigcirc \times M$. saxatilis §ో). Aquaculture, v.161, p.187-199, 1998.

KROGDAHL, A.; HEMRE, G-I.; MOMMSEN, T.P. Carbohydrates in fish nutrition: digestion and absorption in postlarval stages. Aquacult. Nutr., v.11, p.103-122, 2005.

LAZZARI, R.; RADÜNZ NETO, J.; PEDRON, F.A.. et al. Desempenho e composição dos filés de jundiás (Rhamdia quelen) submetidos a diferentes dietas na fase de recria. Arq. Bras. Med. Vet. Zootec., v.60, p.477-484, 2008. 
LIN, J.H.; CUI, Y.; HUNG, S.S.O. et al. Effect of feeding strategy and carbohydrate source on carbohydrate utilization by white sturgeon (Acipenser trasmontanus) and hybrid tilapia (Oreochromis niloticus x $O$. aureus). Aquaculture, v.148, p.201-211, 1997.

LOSEKANN, M.E.; RADÜNZ NETO, J.; EMANUELLI, T. et al. Alimentação do jundiá com dietas contendo óleos de arroz, canola ou soja. Cienc. Rural, v.38, p.225-230, 2008.

MÉDALE, F.; GUILLAUME, J. Nutritional energetics. In: GUILLAUME, J.; KAUSHIK, S.J.; BERGOT, P. et al. Nutrition and feeding of fish and crustaceans. Springer Praxis, Chichester, 2001. cap. 5, p.59-80.

MEYER, G.; FRACALOSSI, D. M. Estimation of jundiá (Rhamdia quelen) dietary amino acid requirements based on muscle amino acid composition. Sci. Agric., v.62, p.401-405, 2005.

OFFICIAL methods of analysis. 16.ed. Washington, DC: AOAC, 1995. Supplement 1998.

PEDRON, F.A.; RADÜNZ NETO, J.; EMANUELLI, T. et al. Cultivo de jundiás alimentados com dietas com casca de soja ou de algodão. Pesqui. Agropecu. Bras., v.43, p.93-98, 2008.

PERES, H.; OLIVA-TELES, A. Utilization of raw and gelatinized starch by European sea bass (Dicentrarchus labrax) juveniles. Aquaculture, v.205, p.287-299, 2002.

RAWLES, S.D.; LOCHMANN, R. Effects of amylopectin/amylose starch ratio on growth, body composition and glycemic response of sunshine bass Morone chrysops $q \times$. $\times$. saxatilis $\hat{\jmath}$. J. World Aquacult. Soc., v.34, p.278-288, 2003.

SALHI, M.; BESSONART, M.; CHEDIAK, G. et al. Growth, feed utilization and body composition of black catfish, Rhamdia quelen, fry fed diets containing different protein and energy levels. Aquaculture, v.231, p.435-444, 2004.
SHIAU, S.Y. Utilization of carbohydrates in warmwater fish - with particular reference to tilapia, Oreochromis niloticus $\times O$. aureus. Aquaculture, v.151, p.79-96, 1997.

SINGH, R.K.; BALANGE, A.K.; GHUGHUSKAR, M.M. Protein sparing effect of carbohydrate in the diet of Cirrhinus mrigala (Hamilton, 1822) fry. Aquaculture, v.258, p.680-684, 2006.

STATISTICAL analysis system: user's guide - SAS. Cary, NC: SAS Institute, 2001.

SVIHUS, B.; UHLEN, A.K.; HARSTAD, O.M. Effect of starch granule structure, associated components and processing on nutritive value of cereal starch: a review. Anim. Feed Sci. Technol., v.122, p.303-320, 2005

VENOU, B.; ALEXIS, M.N.; FOUNTOULAKI, E. et al. Effect of extrusion of wheat and corn on gilthead sea bream (Sparus aurata) growth, nutrient utilization efficiency, rates of gastric evacuation and digestive enzyme activities. Aquaculture, v.225, p.207-223, 2003

WILSON, R.P. Utilisation of dietary carbohydrate by fish. Aquaculture, v.124, p.67-80, 1994.

WU, X.Y.; LIU, Y.J.; TIAN, L.X. et al. Utilization of different raw and pre-gelatinized starch sources by juvenile yellowfin seabream Sparus latus. Aquacult. Nutr., v.13, p.389-396, 2007.

YOUNG, A.; MORRIS, P.C.; HUNTINGFORD, F.A. et al. Replacing fish oil with pre-extruded carbohydrate in diets for Atlantic salmon, Salmo salar, during their entire marine grow-out phase: Effects on growth, composition and colour. Aquaculture, v.253, p.531-546, 2006.

ZHOU, X.; KAPLAN, M.L. Soluble amylose cornstarch is more digestible than soluble amylopectin potato starch in rats. J. Nutr., v.127, p.1349-1356, 1997 